\title{
És o que podias ter sido? Sobre como os jovens contemporâneos são convocados ao inverossímil
}

\author{
Lina Raquel Marinho \& Lana Veras \\ Universidade da Beira Interior / Universidade do Estado do Rio de Janeiro \\ E-mail: Lina_usa76@hotmail.com/Lanaveras@hotmail.com
}

\begin{abstract}
Resumo
Construiremos uma análise crítica e conjectural a partir de um estudo bibliográfico, acerca do capitalismo contemporâneo, seus mecanismos de violência socioeconômica e seu caráter predatório. Partiremos da análise de duas peças publicitárias veiculadas na cidade de Lisboa, que primeiro responsabilizam seus jovens e depois os convocam ao inverossímil das possibilidades meritocráticas individuais seus jovens diante da sociedade capitalista e suas conquistas e realizações. Estes jovens são parte de uma lógica cuja gestão da informação e do conhecimento está também a serviço da sociedade do valor que transforma todas as esferas da vida em mercadoria,

dores, e na qual os produtos, são os únicos meios de se assegurar a projeção e mediação/realização da própria subjetividade no mundo. Autores como Anselm Jappe, filósofo alemão e estudioso de Debord, e Robert Kurz, também filósofo e ensaísta alemão membro do grupo de estudos e pesquisa Krisis, entendem que são as contradições e limitações internas do capitalismo, agudizadas em sua fase atual ou mais tardia de produtividade, liberação de mão de obra, queda no valor gerado versus necessidade permanente de sempre gerar mais valor e finitude dos recursos planetários, que tornam esta lógica cada vez mais violenta e cuja própria ontologia passa a ser a barbárie.
\end{abstract} seus indivíduos em invariáveis consumi-

Palavras-chave: Capitalismo; meritocracia; mercantilização; sociedade do valor e informação.

\begin{abstract}
We are going to build a critical and conjectural analysis based on a theoretical study towards the contemporary capita-

lism, its social and economical mechanisms of violence and its predatory character. Considering from the exam of
\end{abstract}


two advertising pieces promoted in Lisbon that first charge their youth and then after call upon individual unlikely meritocratic possibilities, their youth once facing the capitalistic society and their conquers and acquirements. These young are part of a logic in which the information and knowledge management is also in service of the so called valuing society that is able to transform all life dimensions into merchandise, all individuals in inescapable consumers, and in which the products, are the only way to assure the projection and mediation/accomplishment of the own subjectivity in the world. Authors as Anselm
Jappe, a German philosopher and a Debord researcher, and Robert Kurz, also a German philosopher and essayist, member of the researching group: Krisis, they understand that the internal contradictions and limitations of the capitalism itself, taken into extreme, sharpened in its most actual or later producing phase, causing labour dispense, fall of the value generated versus the permanent necessity of always generating more value and the planetary finiteness of the sources, that these transform the logic in an each time more violent logic, where its own ontology becomes the barbarism.

Key-words: Capitalism; meritocracy; commodification; valuing society and information.

\section{Uma convocação, um discurso, uma ação}

TÁ está escuro quando Pedro entra na estação de metrô, ainda é inverno em Lisboa e ele se apressa para conseguir entrar no último vagão. Próxima estação: Rossio.

Senta-se em frente à Joana e, devido à calefação, pode tirar o seu casaco mais pesado. Fazer entregas de moto a essa época fria deve ser muito desgastante, pensa Joana sobre o trabalho de Pedro, ao ler seu crachá de uma rede de fast-food com o cargo "Entregador". Pedro fica um pouco constrangido quando percebe que Joana lê o seu crachá, e fica a pensar de onde viria moça tão "gira", com altivez de princesa? Próxima estação: Restauradores.

Joana vinha do seu plantão como operadora de telemarketing, em silêncio pensava sobre suas metas não cumpridas naquele dia extenuante de trabalho, metas de vendas de seguros. Próxima estação: Avenida.

Muitas pessoas entram no vagão a cada estação, afora os turistas com sacolas e sorrisos, a maioria retorna para casa após um dia de trabalho, ou de busca por ele, e o metrô se demora um pouco mais na estação da Avenida da 
És o que podias ter sido? Sobre como os jovens contemporâneos são convocados ao inverossímil

Liberdade. Pedro olha pela janela da sua direita e vê uma peça publicitária que chama muito sua atenção. Joana olha pela janela da sua direita e vê uma peça publicitária que chama muito sua atenção.

Aquela propaganda parece falar diretamente com eles e os inquire: "És o que podias ter sido?"

A imagem publicitária que captura Pedro (figura 1), um grande capacete híbrido metade astronauta com a inscrição "As tuas ambições" e metade entregador de pizza com a inscrição "As tuas habilitações", não deixa nenhuma dúvida: ele fracassou.

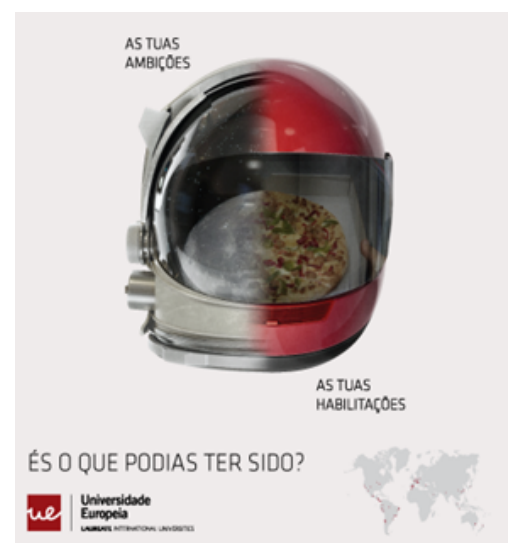

Figura 1. Publicidade veiculada no metro de Lisboa no primeiro semestre de 2015

A imagem publicitária que captura Joana (Figura 2), uma graciosa coroa de princesa, ao lado da legenda "As tuas ambições", logo sofre uma mutação e, ao lado de "As tuas habilitações" o que é mostrado a Joana é um fone de operadora de telemarketing. Não há nenhuma dúvida sobre seu fracasso: a responsabilidade por ele é dela. Próxima estação: Marquês de Pombal. 


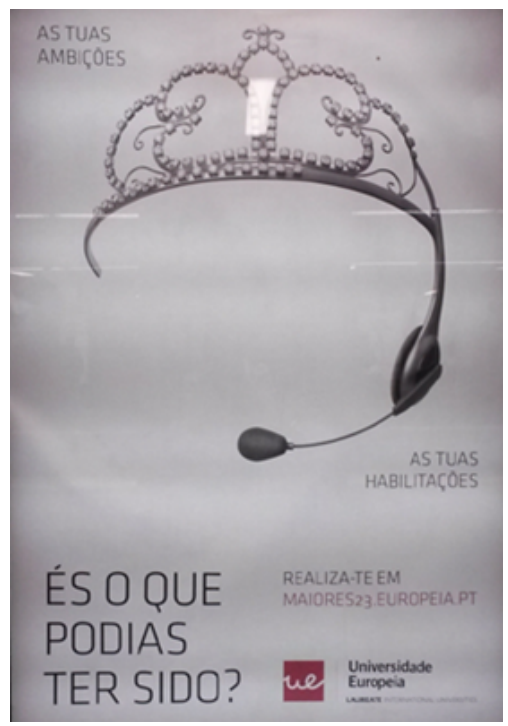

Figura 2. Publicidade veiculada no metro de Lisboa no primeiro semestre de 2015

Pedro olha para a bota de Joana, que, por sua vez, fita a mochila de Pedro, no chão. Próxima estação: Parque. És o que podias ter sido? Próxima estação: São Sebastião. És o que podias ter sido? Próxima estação: Praça de Espanha. És o que podias ter sido? Próxima estação: Jardim Zoológico. És o que podias ter sido? Próxima estação: Laranjeiras...

Os pensamentos de Pedro somente são interrompidos quando da risada do senhor que lê um livro, sentado ao seu lado. Quase que discretamente, Pedro consegue ler uma parte da História:

"De como o Barão salva-se a si mesmo e a seu cavalo puxando-se pela trança do cabelo para fora do lamaçal."

Diz a fábula:

"De outra feita eu quis pular sobre um lamaçal, que de primeiro não me pareceu tão largo. No meio do salto, no entanto, me dei conta de seu verdadeiro tamanho. Suspenso no ar, me virei, e voltei para donde saíra, a fim de tomar maior impulso. Entretanto, voltei a pular muito 
És o que podias ter sido? Sobre como os jovens contemporâneos são convocados ao inverossímil

pouco pela segunda vez e caí no lamaçal, afundando até o pescoço, não muito distante da margem oposta. Eu estaria irremediavelmente perdido naquela situação, não tivesse a força do meu próprio braço me agarrando pela minha própria trança e me puxado, junto com meu cavalo, que abracei com força entre meus joelhos, para fora dali."

Joana, por sua vez, conseguiu ler o título do livro: "As surpreendentes aventuras do Barão de Munchausen".

Publicado inicialmente em 1895, o texto de Rudolph Erich Raspe divulgou histórias atribuídas ao citado Barão, também conhecido pela alcunha de o maior mentiroso de todos os tempos. A obra tem novas edições ainda hoje e continua cativando leitores com seu conteúdo adjetivado comumente de: fantástico, inverossímil, impossível, fantasioso, inexequível, infactível, extraordinário ou impraticável.

Joana e Pedro desembarcam do metro e seguem rumo às suas casas, às suas rotina possíveis. Mas carregam consigo o fardo que o encontro com as descritas propagandas, de uma rede mundial de universidades particulares, os deixou.

A que aquelas peças publicitárias convocavam Joana e Pedro?

Sim, elas demandavam deles um ato fantástico, inverossímil, impossível, fantasioso, inexequível, infactível, extraordinário ou impraticável. Na volta de um dia de trabalho precarizado o que aqueles jovens recebiam era uma cobrança para que eles próprios se puxassem do pântano onde estavam, se erguessem pelos próprios cabelos! E mais, eram cobrados a salvar a eles próprios e, ainda, a seus cavalos.

Parece-nos incrível que uma solução que tenha causado riso a tantos leitores das "Surpreendentes aventuras do Barão de Munchausen", pela sua implausibilidade, possa ser imperativamente solicitada a esses jovens. Eles passam da ambição, também construída socioculturalmente, de ser princesa ou astronauta, à realidade de inglórios trabalhadores. Além de serem, violentamente, colocados no papel de únicos responsáveis por seu afundamento na lama do pântano.

Não há, no percurso de Pedro e Joana, uma voz que lhes leve a refletir, a perguntar: "-Porque há pântano? -Porque sou eu que estou a afundar nele enquanto outros estão em terra firme e declaram, em tom de obviedade, "-Ele poderia se puxar pelo cabelo se quisesse, se se esforçasse... veja só o exemplo do Barão, ele lutou, conseguiu por ele mesmo, por seus próprios méritos!!”. 
Assim, sem nenhuma relação com o "mundo como ele é", onde os corpos ainda estão submetidos à lei da gravidade, ao contexto social, a alternativa imposta de "puxar-se pelos próprios cabelos" tem recebido a denominação de meritocracia.

O processo de naturalização de diferenças que, em verdade, são sociais, utilizando o axioma da neutralidade, acaba encobrindo condicionamentos históricos, sociais e econômicos. (Löwy, 1994) Determinantes que não são os únicos fatores, pois aqui não pretendemos desincumbir o sujeito de suas responsabilidades proporcionais, percebemos e valorizamos suas potencialidades de se erguer e de se refazer, no entanto, como Brecht fala até em seu poema dedicado às crianças "Ameixeira", há que ser potência, mas há que existir possibilidade.

A ameixeira

No pátio tem uma ameixeira Pequena, não existe menor Para ninguém nela pisar, Puseram grade ao redor

Deseja se desenvolver Encorpar, ficar bem maior Mas nunca poderá crescer Sem receber a luz do sol.

Difícil saber se é ameixeira, Pois ameixas ainda não há, Mas é ameixeira, com certeza,

Pelo tipo de folhas que dá.

Há que existir possibilidades capazes de aflorar, ou melhor acolher e resguardar a prática de múltiplas e plurais potências igualmente possíveis. Isso porque na verdade há mesmo muitas possibilidades disponíveis, mas estaríamos voluntariamente subordinados àquilo que autores como Jappe e Kurz entendem por sociedade do valor.

Será preciso, porém ir e vir dialeticamente diante deste argumento, caso contrário, estaremos mais uma vez perante os inverossímeis travestidos de possibilidades e perante os pântanos nos quais nos arremessam e não necessariamente nos quais nos atiramos. Isso porque, e a priori e inclusive talvez nem acreditemos na existência destes. 
És o que podias ter sido? Sobre como os jovens contemporâneos são convocados ao inverossímil

Desta sociedade do valor resulta nosso quadro seja de possibilidades, ou seja, daquilo que se pensa e pretende que sejam possibilidades diretamente, mas todas orientadas à finalidade única de gerar valor nesta sociedade e em nada em diálogo com as reais potências de cada "ameixeira" assim reconhecida só pela folha, ou seja, de cada subjetividade.

\section{Um projeto: a sociedade do valor}

Esta sociedade do valor é produto e produtora da própria lógica do capitalismo e ela se organiza ou se sustenta com base em dois elementos fundamentais: o trabalho humano e a expansão. Visa-se uma única coisa: gerar valor para e por gerar valor. Há tempos não se gera mais valor para ou por seu real e mediador valor de uso/utilidade no mundo, capaz de transferir a este nossa representatividade existencial e subjetiva. Na verdade somos, nós mesmos, entidades de valor e nossa "mundanidade" se faz presente naquilo que nos objetiva, é por isso que todo dispêndio de energia humana para a produção desta "mundanidade" resulta em valor, ou seja, transparece o valor da entidade produtora, do sujeito que se empregou naquele seu fazer mundo e fazer no mundo.

Esta configuração imanente dos sujeitos no mundo se afasta, porém deste seu projeto originário e aos poucos vai derivando em outras dimensões e esferas quando as entidades de valor decidem gerá-lo com finalidade nele próprio para acumular unidades deste excedente para poder gerar mais valor com as mesmas finalidades em si.

Aos poucos nosso projeto de "mundanidade" afasta-se de nossas importâncias mais diversas, plurais e subjetivas e passa a representar uma entidade externa a nós mesmos, mas que só existe em referência à nossa humanidade no mundo: o próprio valor em si travestido de entidade autônoma e necessariamente e a partir de então traduzido monetariamente pela forma dinheiro.

Atualmente esta mesma sociedade esbarra, porém em seus próprios fundamentos de base, ou melhor esbarra-se com estes fundamentos de maneira e por vias da oposição. Há uma contradição interna destes e nestes elementos posto que o capitalismo tecnológico só faz liberar trabalho em prol da produtividade e um movimento de expansão infinito num planeta de biodiversidade e recursos finitos, inclusive do ponto de vista do elemento humano, e que é tão irreversível e inexorável quanto diversos outros traços desta, esta contínua, 
ilimitada e crescente expansão é tão igualmente impraticável quanto aquilo a que socialmente a lógica da sociedade do valor vai nos convidando e impondo a, para que possa se sustentar e resistir.

Para podermos desenvolver este raciocínio por partes é preciso destacar que a dinâmica de constituição, funcionamento e institucionalização do capitalismo e sua sociedade do valor não é algo pertencente aos traços do capitalismo contemporâneo atual. O traço histórico do capitalismo e da sociedade do valor sempre foi este, tal qual estruturado e organizado sob as formas do trabalho humano e da expansão. O trabalho como a única intervenção do homem no mundo capaz de gerar o valor desejado e perseguido, e a expansão como uma máxima que impulsiona a busca por novos recursos naturais disponíveis à intervenção do trabalho humano, contínua e ilimitadamente. (Kurz, 1998)

O trabalho humano diz respeito, por sua vez, àquela dimensão da vida ativa, como nos coloca Arendt (2013), por exemplo, condicionada ao próprio e simples fato de estarmos vivos, e se ocupa da nossa apropriada manutenção biológica e orgânica. Dimensão da nossa vida ativa, esta sim, alienante e impositiva. Queremos dizer, a despeito do quanto nos identifiquemos subjetivamente ou estejamos em essência ou vocação, representados e projetados nos rituais de sobrevivência orgânica que nos envolvem o tempo diariamente, precisamos dedicar-nos, todos invariavelmente a esta sobrevivência, caso contrário e literalmente não sobramos ou resistimos vivos para o desfrute das outras dimensões possíveis de uma vida ativa.

Além destas questões em torno do trabalho, e cujo termo aparece traduzido na edição brasileira de 2013 do livro A Condição Humana por labor, para a Arendt (2013), haveria ainda as dimensões da obra (work) e ação. Em ambas dimensões estaria o sujeito em condição de plena liberdade para eleger como e por quais vias mediar-se, representar-se e fazer-se presente, histórico e imortal, no mundo.

A obra é da esfera da vocação, como de um artífice, por exemplo, e cuja finalidade de seu produto é sempre a utilidade ao outro daquilo, a obra traz consigo traços de virtuosidade quando se coloca no lugar do outro, suas possíveis e prováveis necessidades, e busca contribuir para o bem-estar e operacionalização real e concreta deste. As obras trazem consigo as crenças e os "valores" de seus "homo faber" e cujo valor é estabelecido pela utilidade e 
És o que podias ter sido? Sobre como os jovens contemporâneos são convocados ao inverossímil

funcionalidade demonstrada nos atos da troca destas obras, sendo inclusive o espaço destas trocas imanentemente público.

A ação, por sua vez, seria a dimensão da vida ativa, que na esteira das relações estabelecidas nos ambientes e a partir das atmosferas de trocas, estaria necessariamente condicionada pela pluralidade dos sujeitos e cuja tradução prática ou práxis direta seria o discurso, verbal ou não verbal, espontâneo ou institucionalmente enquadrado, informal, semi-formal ou formal e mais ou menos, e especialmente em respeito à nossa atualidade, tecnologicamente mediatizado ou não.

De todas as dimensões da vida ativa dos sujeitos aquela inerentemente política seria, portanto e justamete a ação. O que sustenta e permite que sempre desponte entre as relações, a própria condicionante da ação: a pluralidade, e a experiência da convivialidade. Ou seja, a própria noção ética das relações e existência, também pela preservação desta pluralidade, para então estar novamente assegurada, das dimensões mais políticas e subjetivas das relações humanas: a própria ação. Uma ontologia das mais fenomenológicas do ser no mundo, uma livre e consciente "presença-aî", quase uma experiência de transcendência. (Arendt, 2013)

E por todas estas razões, a ação é a dimensão mais política da vida ativa porque é aquela cuja manifestação está diretamente ligada a um coletivo que pretende se constituir e estar no mundo coletivamente e cujo próprio sentido e a própria práxis depende disso, vocalizando sua própria pluralidade a fim não de organizá-la de um ponto de vista político especificamente institucional, mas a fim de (com)quistar a partir desta pluralidade social a própria expressão e manifestação das diferenças.

Em uma sociedade, porém cujo objetivo exclusivo passa a ser gerar valor, e sendo o trabalho humano (labor e work) o único capaz disto, é preciso que primeiramente tudo vire, ou seja, entendido, vivenciado e experimentado, como trabalho. Isto primeiramente porque se quer vincular permanentemente e de forma naturalizada e naturalizante o homem ao seu trabalho (labor) e segundo porque todas as esferas da vida passam a exigir o estabelecer de um determinado valor para viabilizar as inúmeras possíveis trocas despontantes em nossas relações humanas, então e consequentemente também aprisionadas nesta dimensão, ou seja, a partir também desta hegemonia e homogeneidade quantificadora que se torna o próprio valor. (Kurz, 1998) 
Não por acaso a nossa trilha histórica da secularização vai dos vários deuses naturais, passando ao Deus único cristão, chegando ao homem como cocriador racional e iluminado do mundo - a própria prática da vontade do espírito, como nos colocaria Hegel (1999), o que alcança por fim e então, a ideia do próprio trabalho humano (labor e work). Isto aparece claramente entre autores e debates da época como no livro: "A ética Protestante e o Espírito do Capitalismo" de Weber do início do século XX. Todo o projeto civilizatório da humanidade passa a estar condicionado pelo trabalho (labor), mas esta era apenas uma das dimensões da nossa vida ativa.

\section{Uma resultante: a sociedade do trabalho no capitalismo}

Há uma consequente compressão da vida ativa, e ação e obra (work), passam também à condição de trabalho humano (labor) para que possam resultar em produtos de valor: aquele plausível de ser monetariamente traduzido, como já explicitado, pela forma dinheiro. Sejam eles para atender nossos imperativos orgânicos a partir dos quais estamos condicionados pelo simples fato de estarmos vivos, sejam eles obras que nos imortalizam e representam historicamente no mundo, uma vez que estamos condicionados pela temporalidade, uma temporalidade de caráter irreversível, sejam eles entidades do discurso tradutor e expressão da práxis ação, todos estes "produtos" tem seu valor estabelecido conforme o volume, ou a quantidade de trabalho humano (labor) dedicado a eles num intervalo específico de tempo " $\mathrm{t}$ ". (Arendt, 2013)

Consequentemente num mundo onde tudo é trabalho, tudo passa ou precisa passar também a ser produto e mercadoria. Como isto se agudiza, e como o projeto civilizatório da sociedade humanista, iluminada, regida pelo seu deus da razão é transformado em barbárie e violência é o que majoritariamente nos interessa diante deste capitalismo contemporâneo, capaz por sua vez de produzir peças publicitárias tais quais destacadas. Incitando o sujeito a reconhecer seu valor subjetivo apenas através de uma de suas funções sociais: o trabalho, fazendo-o acreditar que de todas as suas funções sociais possíveis, esta é aquela que unicamente importa, e determinando que o valor que ele produz a partir de seu trabalho só depende do próprio valor que ele tem a oferecer e a imputar neste, como se o seu trabalho ainda de fato o representasse e estivesse livre para servir às suas finalidades mais plurais. 
És o que podias ter sido? Sobre como os jovens contemporâneos são convocados ao inverossímil

O discurso que é a tradução prática da ação, tal como, por exemplo, aparece nestas peças publicitárias, é apropriado pela sociedade do valor das mais perversas e alienantes formas, ou seja, afastando o próprio discurso de sua competência enquanto ação política, ou seja, a natureza inerente daquilo que coletiviza por estar condicionado à pluralidade.

Primeiro por ser a quem resta esta dimensão da vida ativa: a ação, a todos nós nos resta apenas trabalho (labor), segundo porque se apropria da essência mais imanente e originária da significação antropológica e vocacionada de trabalho (work) para o sujeito, para "convidá-lo" a este mesmo trabalho, onde work é transformado em labor. O trabalho com qual o sujeito realmente se encontra em seu cotidiano está completamente esvaziado deste seu projeto de origem.

Vale destacar que uma vez intencionalmente suprimidas as dimensões da obra (work) e da ação das nossas expressões de vida ativa, ou melhor uma vez transformando estas dimensões em uma única entidade subjetiva objetivante e alienadora: a do trabalho (labor), nós terminamos paradoxalmente representados pela dimensão menos apta a fazê-lo, pela dimensão mais alienante, menos livre e consciente, simplesmente condicionada pela vida orgânica num a priori e que não se coloca diante do homem ou permite que ele o faça diante deste imperativo orgânico em sua máxima potência crítica, voluntária e autônoma. Por exemplo, ainda que possa escolher o que comer, o homem não pode escolher não sentir a fome que lhe é biologicamente estabelecida e que está contida em seu organismo vivo, em algum momento sentirá fome e não lhe caberá uma ação ou discurso crítico, por exemplo, para com esta para que simplesmente esta deixe de se manifestar nele.

As nossas outras dimensões de vida ativa que estariam justamente a serviço da desalienação destes imperativos, ou seja, sem estas outras dimensões ou as experienciando a partir da formatação do trabalho para gerar valor, perdemos as tais possibilidades que haveria disponíveis às nossas escolhas críticas, aquelas capazes de assegurar que pudéssemos nos implicar no mundo afetivamente.

Quando todas as esferas da nossa vida são transformadas em produtos ou mercadorias de satisfação efêmera aos moldes do que seriam os produtos do trabalho (labor) pela nossa sobrevivência e existência orgânica, toda a nossa presença no mundo se equipara em nível de satisfação e efemeridade, nossas obras e ações são mercadorias cujo valor é estabelecido pela quantidade de 
trabalho humano ali imputado e cujo propósito é gerar este valor, cuja funcionalidade será melhor operacionalizar nossas vidas para gerarmos mais valor porque vivemos de gerá-lor e acumulá-lo, logo está dado e prontamente resolvido todo o caráter motivacional de nossa existência. (Jappe, 2006)

De volta às questões da barbárie e da violência desta lógica e para melhor explicarmos como resultamos nisso precisamos compreender que tudo se desdobra a partir das reais contradições internas do próprio capitalismo.

O desenvolvimento e crescimento da sociedade do valor, impulsionados ideologicamente pela própria máxima da geração contínua, crescente e ilimitada deste valor, resultam em desenvolvimento produtivo, de produtividade e tecnológico, mas estes dispositivos que atendem às tendências da própria modernização do capitalismo ao aumentarem a produtividade liberam trabalho humano, é a clássica substituição histórica dos homens pelas máquinas.

Mas, se somente o trabalho humano é capaz de gerar valor, e por isso o homem é levado às fábricas para se dedicar incansavelmente à geração de valor em troca de uma remuneração compensatória e que lhe permitiria por sua vez adquirir o bem cuja valoração dependeu exatamente do trabalho também de outros, se este trabalho humano é liberado e a máquina passa a produzir o bem ou a mercadoria, inevitavelmente o seu valor decresce e disso resulta que será preciso um conjunto maior de bens para que se possa acumular um mesmo montante de valor. (Kurz, 1998)

Esta é sua primeira e mais primária contradição: depender do trabalho humano para gerar o valor que deseja acumular e liberar trabalho humano à medida que o valor que gera se moderniza e desenvolve.

Somado a isto temos os limites geográficos e naturais que hoje esta sociedade do valor enfrenta a respeito de suas possibilidades de expansão. Não há mais para onde se expandir ilimitadamente, como quando se imaginava ser à época da colonização, por exemplo, e cujo movimento de contínua expansão assegurava ao capitalismo a reabsorção de todo o trabalho humano liberado nas novas regiões que eram, pois palcos eminentes do desenvolvimento da produtividade até que fosse chegado o momento do novo movimento ou salto de expansão.

Os pares possíveis das regiões desenvolvidas àquelas a se desenvolverem, na teoria se esgotaram e na prática para que se concretizassem, hoje, exigiriam efetiva redistribuição de riqueza e volume de valor acumulado de maneira concentrada. 
És o que podias ter sido? Sobre como os jovens contemporâneos são convocados ao inverossímil

A saída para nós é perceber que não há uma saída senão um exercício de crítica radical desta sociedade e sua lógica.

A saída é dizermos não aos múltiplos pântanos nos quais querem nos arremessar recusando a lógica que nos responsabiliza por eles e que nos obriga à forma hegemônica da individualidade, mas como operacionalizar isto, eis a questão? Dependemos dos nossos trabalhos pela sustentabilidade literal dos nossos imperativos orgânicos e dentre as múltiplas possibilidades da nossa "vida ativa" só nos resta trabalho (labor) para acessarmos todas as nossas esferas de vida privada e pública e que foram igualmente transformadas em mercadorias e produtos.

A propósito esta foi a saída da sociedade do valor: mercantilizar todas as esferas e dimensões de nossa vida, transformar tudo em possível produto resultante de trabalho, inclusive o conhecimento científico, ditando os melhores meios, formatos e estruturações para uma melhor e maior produtividade, de conhecimento.

O dinheiro também foi mercantilizado em forma de capital financeiro e os sujeitos em forma de capital humano. Tudo isto por si só já seriam traços suficientes de barbárie intencionalmente constituída e planejada posto que aliena os sujeitos e faz-lhes escapar a própria vida, mas além disso há todos os desdobramentos da mão de obra desempregada pela constante liberação de trabalho humano, sua marginalização pela impossibilidade de gerar e trocar valor e consequentemente seu despertencimento à lógica e pelo qual somos individualmente e de muitas maneiras violentas cobrados e responsabilizados.

Continua então válido o questionamento feito pelo psicólogo Botomé (2010) ainda no Brasil da década de 70, e repetido integralmente em publicação recente: "A quem devemos "tratar e mudar": O homem que sofre ou as condições que ofazem sofrer ou produziram seu sofrimento?"

\section{Referências}

Arendt, H. (2013). A condição humana. Rio de Janeiro: Forense Universitária.

Botomé, S.P. (2010). A quem nós, psicólogos, servimos de fato?. In O.H. Yamamoto \& A.L.F. Costa (orgs.) Escritos sobre a profissão de psicólogo no Brasil. Natal: EDUFRN. 
Costa, A.L.F. (org.) (2010). Escritos sobre a profissão de psicólogo no Brasil. Natal: EDUFRN.

Hegel, G.W.F. (1999). Filosofia da História. Brasília: Editora Universidade de Brasília.

Jappe, A. (2006). As aventuras da mercadoria: para uma nova crítica do valor. Lisboa: Antígona.

Kurz, R. (1998). Os últimos combates. Petrópolis: Vozes.

Löwy, M. (1994). As aventuras de Karl Marx contra o Barão de Münchhausen: Marxismo e Positivismo na Sociologia do Conhecimento. São Paulo: Editora Cortez.

Raspe, R.E. (1895). As Surpreendentes Aventuras do Barão de Munchause.

\section{Imagens}

www.cunhavaz.com

http://culturvisflul.blogspot.com.br 